\title{
Effect of Stirrups on Behavior of Normal and High Strength Concrete Columns
}

\author{
J. Němeček, P. Padevět, Z. Bittnar \\ This paper deals with an experimental investigation and numerical simulation of reinforced concrete columns. The behavior of normal and \\ high strength columns is studied, with special attention paid to the confinement effects of transversal reinforcement in columns with a square \\ cross section. The character of a failure, and the strengths, ductility and post-peak behavior of columns are observed in experiments and also \\ in numerical solution. A three-dimensional computational model based on the microplane model for concrete was constructed and compared \\ with experimental data. The results of the numerical model showed good agreement in many aspects, and proved the capabilities of the used \\ material model.
}

Keywords: concrete, reinforced concrete columns, stirrups, normal strength concrete, high strength concrete, experiments, simulation, microplane model.

\section{Introduction}

Nowadays, attention in civil engineering is focused on high performance structural materials. Like it or not, concrete is still a world wide leading structural material. Typically, it is used in columns (due to its high bearing capacity in compression) in high-rise buildings. The high performance of the material also tends to substantial questions concerning not only the bearing capacity, but also its ductility and post-peak behavior. High strength concrete members usually suffer from lower ductility. Thus, special attention must be paid to the post-peak behavior of such columns, because reduction of ductility can lead to a significant reduction of the overall load bearing capacity of the structure during abnormal loading, such as earthquake or a terrorist attack, for example. The problem of concrete ductility is complicated by dependence on the amount of confinement, i.e. the amount of transversal reinforcement. This concerns both high and normal strength concretes. A better understanding of concrete behavior in reinforced concrete structures such as columns is needed, and precise and verified models are required.

During the past decade, many authors have investigated the load bearing capacity of columns and the confinement effects of reinforcement. However, these studies have been oriented mainly to strength investigations. Less is known about the post-peak behavior of such columns. Moreover, studies are limited mainly to circular cross sections, where the effect of confinement is very significant. Fam and Ritzakalla [9] investigated a series of small to large-scale circular columns cast into steel and composite tubes. They showed the importance of lateral confinement, what can lead to more than a $100 \%$ strength increase. Unfortunately, no post-peak investigation was performed. Similar results were obtained by Mortazavi et al. [16] for concrete columns with pretensioned carbon fiber polymer tubes. Existing knowledge about the design of steel confined concrete is already incorporated in Eurocode 8 [8]. It assumes the confining steel is fully utilized (yielded) and cross sectional aspects are taken into account by the confinement effectiveness coefficient (equal to one for cylindrical cross sections). Some investigations of confinement effects and also of size effect for reinforced concrete columns can be found e.g. in Hollingworth [10], Bažant and
Kwon [1], Sener et al. [21]. However, these works concern mainly strength issues and not the ductility.

\section{Motivation}

Eccentrically loaded reinforced concrete columns were chosen for this research. Centric loading would not be suitable for our research, especially when post-peak behavior is the matter of investigation (e.g. Němeček [13], [14]). The choice of columns was influenced by the following facts. A column is a typical structural element, which is used multiple times in the structure. It has an enormous influence on the ductility and overall performance of the structure. A combination of compression with small eccentricity produces a relatively complicated triaxial stress state in the concrete, which is longitudinally and transversally reinforced. The character of the failure can be readily observed and measured. Measured parameters can be compared with the model simulation. All these considerations made the column a perfect candidate for this study.

\section{Methods}

We decided to study the problem both experimentally and numerically. One typical geometry with a square cross section was chosen for all tested columns. The columns were reinforced with the same amount of longitudinal reinforcement and a variable amount of transversal reinforcement (stirrups). Three different distances of stirrups were used. Two concrete grades (normal and high strength) were tested. Thus, the total number of studied cases was 6 .

A three-dimensional finite element model for columns was constructed. Some sophisticated three-dimensional material model, capable of describing all important natural phenomena (such as tension and compression softening, path dependence, anisotropy and so on), had to be used. The M4 microplane model (Bažant et al. [5], Caner and Bažant [6]) was our choice. The use of this model was justified for similar applications (Brocca and Bažant [7], Němeček and Bittnar [13]). The problem was studied using the OOFEM finite element package [11] developed at the Department of Structural Mechanics, CTU Prague. 


\section{Experiments}

\subsection{Specimens}

A common geometry for all columns was used. The columns had a square cross section $150 \times 150 \mathrm{~mm}$ and length $1150 \mathrm{~mm}$. The longitudinal reinforcement (ribbed bars with a diameter of $12 \mathrm{~mm}$ ) was placed into the corners of the cross section. The transversal reinforcement was formed by closed stirrups with a diameter of $6 \mathrm{~mm}$. The longitudinal distance between the stirrups at the middle part of the columns was 50 , 100 and $150 \mathrm{~mm}$ (these dimensions are used in the subsequent notation of the series, e.g. N50 is a normal strength concrete column with a $50 \mathrm{~mm}$ stirrup distance at the midheight). The distance of the stirrups at the ends was denser to prevent damage in this region caused by introducing the load and by possible geometrical imperfections. The longitudinal reinforcement was further fixed into massive end blocks made of steel (80 $\mathrm{mm}$ in depth) for smooth load transfer. The dimensions of the specimens and their reinforcement is depicted in Fig. 1a. Each series consisted of five identical specimens. The columns were loaded in uniaxial eccentric compression. The eccentricity of the compressive load was $15 \mathrm{~mm}$ (i.e. 0.1 of cross sectional depth).

\subsection{Instrumentation}

Experiments were carried out on a feedback control test machine having a very stiff $12 \mathrm{MN} / \mathrm{mm}$ steel frame and maximum load $2500 \mathrm{kN}$ (Inova DSM2500, CZ). The control was based on a constant increment of longitudinal deformation. Each specimen was equipped with a set of tensometric gauges used for longitudinal strain measurements. Rotary potentiometric gauges were used for midheight lateral deflection measurements. The measured experimental parameters were as follows: overall axial force, midheight lateral deflection, strains measured over the whole length of the column (base $960 \mathrm{~mm}$ ), strains at the ends of the column (base $50 \mathrm{~mm}$ ). The type and character of the failure was also observed. The gauge arrangement is depicted in Fig. 1b.

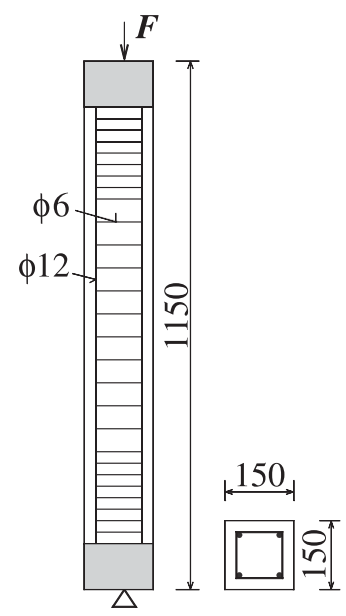

(a)

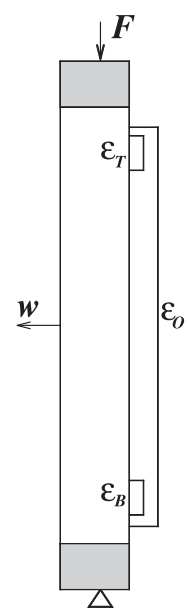

(b)
Fig. 1: (a) Geometry of specimens in $\mathrm{mm}$, (b) gauge arrangement and corresponding measured parameters $(F$ stands for overall force, $w$ stands for midheight lateral deflection, $\varepsilon_{0}$ is overall longitudinal strain and $\varepsilon_{\mathrm{T}}$ and $\varepsilon_{\mathrm{B}}$ are top and bottom strains measured at column ends)

\subsection{Materials}

It was decided to study the confinement effects of stirrups on two grades of concrete: normal ( $\mathrm{N}$ series) and high strength (H series). The concrete mixture proportions are given in Table 1. Uniaxial compression tests on cylinders

Table 1: Concrete mixture proportions $\left(\mathrm{kg} / \mathrm{m}^{3}\right)$

\begin{tabular}{|c|c|c|c|c|c|}
\hline Series & $\begin{array}{c}\text { Aggregate } \\
(0-4) \mathrm{mm}\end{array}$ & $\begin{array}{c}\text { Aggregate } \\
(4-8) \mathrm{mm}\end{array}$ & Cement & Water & Plastisizer \\
\hline $\mathrm{N}$ & 800 & 880 & 350 & 204 & - \\
\hline $\mathrm{H}$ & 800 & 880 & 420 & 120 & 8.4 \\
\hline
\end{tabular}

(diameter $150 \mathrm{~mm}$, height $300 \mathrm{~mm}$, six for each series) were performed. An average measured stress-strain diagram of cylinders is shown in Fig. 2. It is clear that not only the peak strengths but also the ductility are different for the two con-

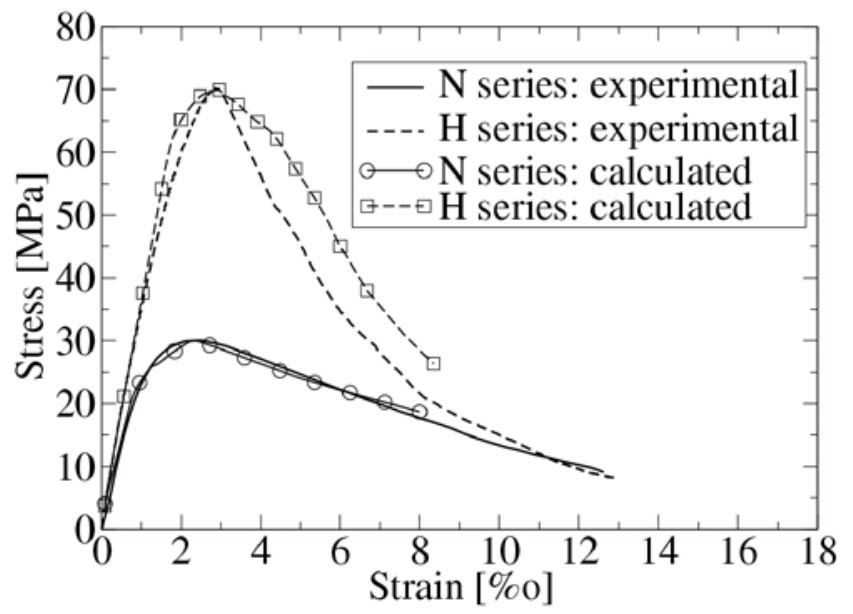

Fig. 2: Stress-strain diagrams measured on cylinders in uniaxial compression tests (mean values) and corresponding computed curves used for calibration of the microplane model

crete mixtures. $\mathrm{N}$ series was much more ductile than $\mathrm{H}$ series as can be seen from the post-peak slope in Fig. 2. Stress-strain diagrams of the cylinders were used for subsequent calibration of the microplane model. The mean strengths and standard deviations for concrete (in uniaxial compression) and steel (in uniaxial tension) are given in Table 2.

Table 2: Mean values of material strengths \pm standard deviations (uniaxial compression for concrete and uniaxial tension for reinforcement, all in $\mathrm{MPa}$ )

\begin{tabular}{|c|c|c|c|}
\hline N series & H series & $\begin{array}{c}\text { Longitudinal } \\
\text { reinforcement }\end{array}$ & Stirrups \\
\hline $30 \pm 1.6$ & $67.2 \pm 3.4$ & $561 \pm 12.2$ & $314 \pm 11.6$ \\
\hline
\end{tabular}

\subsection{Test results}

The behavior of all series was very similar. Almost all specimens failed around the midheight. As an example, all specimens of series N100 after collapse can be seen in Fig. 3 a. Column collapse was initiated by concrete softening at the 


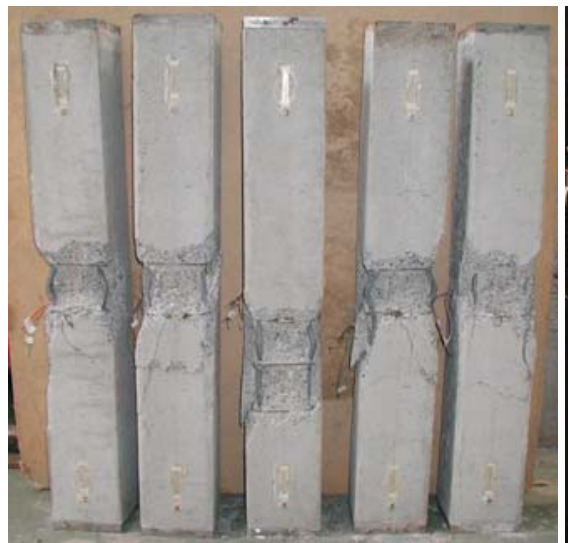

(a)

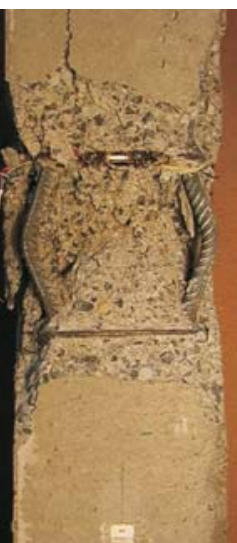

(b)

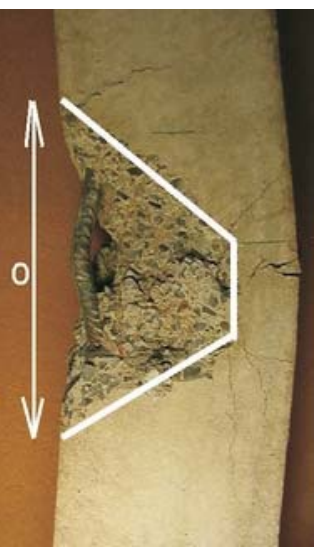

(c)

Fig. 3: Experiments: (a) series N100 after collapse, (b) front view of the damaged zone at the midheight, (c) side view of the damage zone (wedge shape)

midheight, accompanied by symmetric buckling of both reinforcing bars at the compressed side of the cross section. The bars always buckled between stirrups, as can be seen in Fig. 3b. Failure localized at the middle part of the column where a wedge-shaped pattern developed (see Fig. 3 c).

The front longitudinal dimension of the wedge was measured to characterize the size of the damage zone (labeled as $o$ in Fig. 3c). The dimensions of the damage zone for all series are summarized in Table 3. Note that these dimensions are just guide values because it is hard to find a sharp end of the damage zone in concrete and also the final force applied in the column was not absolutely the same for all specimens (loading finished at approximately $30 \pm 10 \%$ of the peak force). However, it can be seen that the damage zone is approximately equal for all series regardless of the density of

Table 3: Dimensions of the wedge-shaped damage zone (all dimensions in $\mathrm{mm}$ )

\begin{tabular}{|c|c|c|c|}
\hline Specimen & Dimension $o$ & Specimen & Dimension $o$ \\
\hline N50 & $250 \pm 11.7$ & H50 & $266 \pm 18.5$ \\
\hline N100 & $256 \pm 18.6$ & H100 & $240 \pm 16.3$ \\
\hline N150 & $196 \pm 15.0$ & H150 & $213 \pm 9.4$ \\
\hline
\end{tabular}

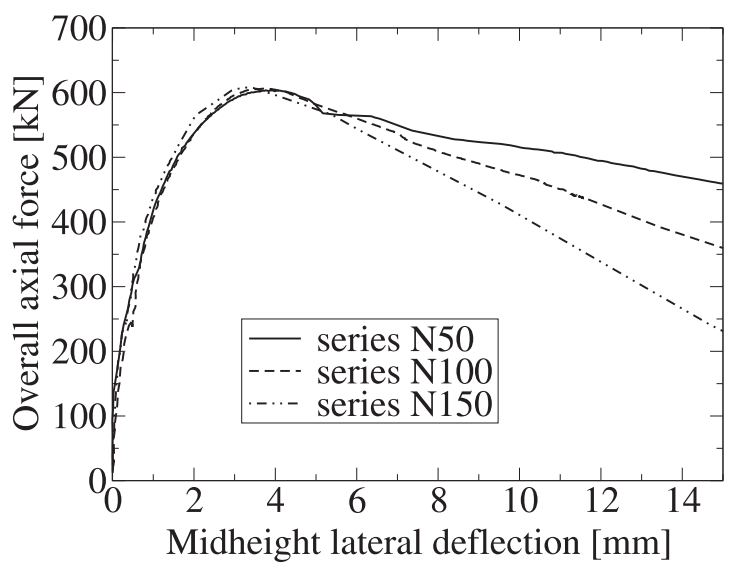

the stirrups. The means that the damage zone runs across one or more stirrups but the damage size remains approximately the same.

The yield plateau in the force-deflection curve was very small and the load-bearing capacity decreased from the peak value. The loading diagrams plotted for overall axial force versus midheight lateral deflection are shown in Fig. 4 for all series. The peak values of deflection and force for all series are summarized in Table 4 . The results show no significant in-

Table 4: Experimental results: mean peak values of midheight lateral deflection and overall axial force \pm standard deviations

\begin{tabular}{|c|c|c|}
\hline & $\begin{array}{c}\text { Peak deflection } w_{\exp } \\
{[\mathrm{mm}]}\end{array}$ & $\begin{array}{c}\text { Peak force } P_{\exp } \\
{[\mathrm{kN}]}\end{array}$ \\
\hline N50 & $3.84 \pm 0.18$ & $617.6 \pm 18.7$ \\
\hline N100 & $3.69 \pm 0.35$ & $607.8 \pm 11.8$ \\
\hline N150 & $3.48 \pm 0.44$ & $602.2 \pm 15.9$ \\
\hline H50 & $2.75 \pm 0.21$ & $1053.2 \pm 45.7$ \\
\hline H100 & $2.71 \pm 0.16$ & $1038.4 \pm 46.2$ \\
\hline H150 & $2.38 \pm 0.41$ & $1007.0 \pm 55.1$ \\
\hline
\end{tabular}

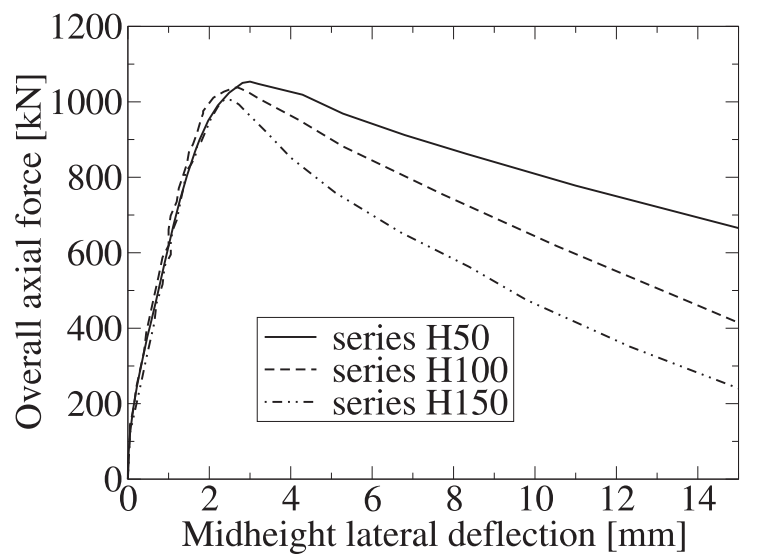

Fig. 4: Experiments: Force vs. midheight lateral deflection diagrams of $\mathrm{N}$ (left) and $\mathrm{H}$ (right) series 
fluence of density of stirrups on the peak values, i.e. strength and strain. However, this dependence occurs in the post-peak region. The ductility characterized by the slope of the force-deflection diagram increases as the distance between the stirrups decreases.

Tensometric measurements of longitudinal strains were also performed. The strain was measured over the whole length of the column and at the ends. The measurements at the ends of columns showed unloading in this area after reaching the peak load (see Fig. 5 where a specimen from the H100 series was taken as an example). This provided a clear evidence of the localization of the deformation in the middle part of the column while the remaining part underwent unloading.

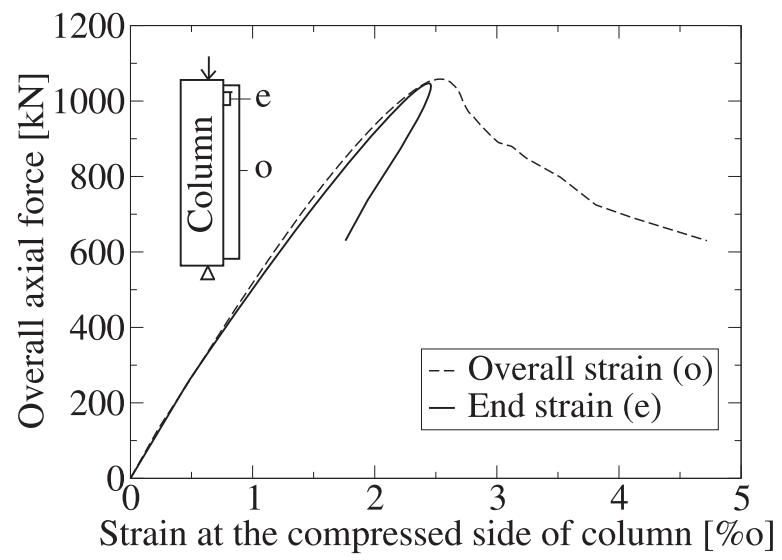

Fig. 5: Strain measured at the compressed side of RC column over the whole length and at the end

\section{Numerical simulation}

\subsection{Computational model}

A three-dimensional finite element model of the specimens was developed. The microplane model M4 (Bažant et al. [5], Caner and Bažant [6]) was chosen as a model for concrete due to its capability to describe many natural phenomena of this material, such as compression and tension softening, path dependence, development of anisotropy and others. It is a conceptually simple but computationally demanding triaxial model. The crucial aspect of a constitutive model of such a kind is proper fitting of the material parameters. The microplane model constitutive relations are based on a set of parameters that have generally no direct physical meaning. By an optimal fitting of standard uniaxial compression tests on cylinders (see Fig. 2) the sets of material para-

Table 5: Material parameters of the microplane model M4 for concrete

\begin{tabular}{|c|c|c|c|c|c|c|c|}
\hline Series & $E$ & $k_{1}$ & $k_{2}$ & $k_{3}$ & $k_{4}$ & $c_{3}$ & $c_{20}$ \\
\hline & MPa & \multicolumn{7}{|c|}{$\begin{array}{r}\text { nondimensional microplane model M4 } \\
\text { parameters }\end{array}$} \\
\hline $\mathrm{N}$ & 33000 & 0.000088 & 500 & 15 & 150 & 4 & 1.0 \\
\hline $\mathrm{H}$ & 46039 & 0.000140 & 500 & 15 & 150 & 4 & 0.4 \\
\hline
\end{tabular}

meters for two concrete grades, $\mathrm{N}$ and $\mathrm{H}$ were found. The appropriate set of material parameters was always used for computations of all specimens of $\mathrm{N}$ series and all of $\mathrm{H}$ series, respectively. The microplane model parameters for concrete are summarized in Table 5 .

Structured meshes were generated for all columns, because only local formulation of the microplane model was used. This means that the energy dissipated from each element must be kept constant in order to receive mesh independent results. Thus, the models consisted of the same size cubic elements in the middle part of the column where the microplane model was used. The end parts of the columns were modeled as elastic to save computational time. The reinforcement was modeled by 3D beam elements with both geometrical and material nonlinearities (J2 plasticity with hardening), in order to capture also yielding and buckling. The FE model of the RC column is shown in Fig. 6. The deformed geometry is depicted in the post-peak phase, where the deformation is already localized in the middle part. The deformed embedded reinforcement buckling at midheight between the stirrups can also be seen in Fig. 6 .
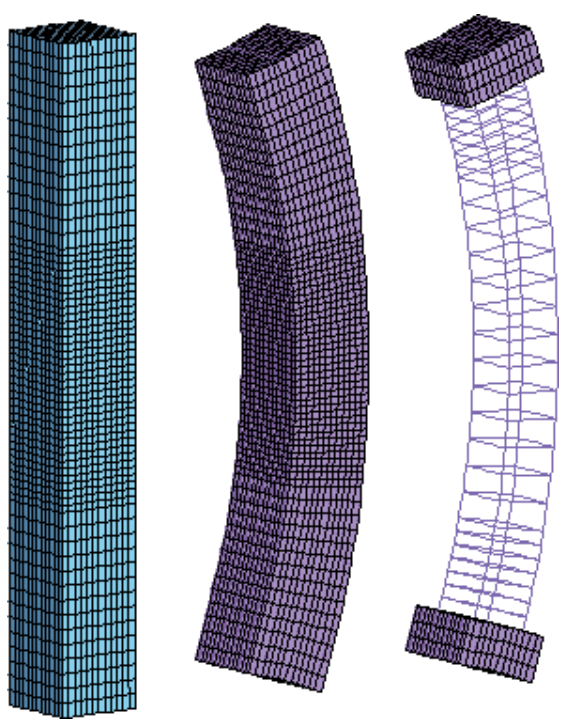

Fig. 6: Finite element mesh: initial geometry, deformed geometry, deformed embedded reinforcement (specimen H50)

Details concerning the FE model and the computational times are mentioned in Table 6 . The number of elements varied only slightly between the 50,100 and 150 series due to the slightly different amount of stirrups. As a side effect, some computational aspects were observed for the model. The computation times are very long on a single processor PC.

Table 6: Details of FE model and computational times (Pentium IV-2GHz, 1 GB RAM)

\begin{tabular}{|c|c|c|c|c|}
\hline Series & $\begin{array}{c}\text { Number } \\
\text { of degrees } \\
\text { of } \\
\text { freedom }\end{array}$ & $\begin{array}{c}\text { Number } \\
\text { of } \\
\text { elements }\end{array}$ & $\begin{array}{c}\text { Number } \\
\text { of } \\
\text { load } \\
\text { steps }\end{array}$ & $\begin{array}{c}\text { Time of } \\
\text { computation }\end{array}$ \\
\hline $\mathrm{N} / \mathrm{H}$ & 33585 & 10024 to 10280 & 10000 & $35: 38 / 55: 10 \mathrm{~h}$ \\
\hline
\end{tabular}


This indicates the high computational complexity of the microplane model. This is the penalty to be paid for such a complex but concise material model. This model feature can be overcome by using a parallel approach, for instance Němeček et al. [15].

\subsection{Structural analysis}

As was mentioned above, the microplane model is very computationally demanding. Moreover, the M4 version of the model gives no direct formulation of the tangential stiffness matrix and the only way is to use the initial elastic stiffness matrix throughout the computation, which gives a very slow convergence. The solution is to use nonlinear dynamic analysis explicit integration (Němeček [14], Němeček et al. [15]). To solve a static loading, we used a special form of the load time function $d(t)$ that minimizes inertia forces (Řeřicha [20]). The formula has the form

$$
d(t)=A\left(3-\frac{t}{T}\right)\left(\frac{t}{T}\right)^{2},
$$

where $T$ is the total time of computation and $A$ is a constant dependent on the final displacement. The load time function was applied as a displacement at the appropriate points at the top of the columns. The problem was solved using the OOFEM FE-code ([11], Patzák [18], [19]) developed at the Department of Structural Mechanics at CTU in Prague.
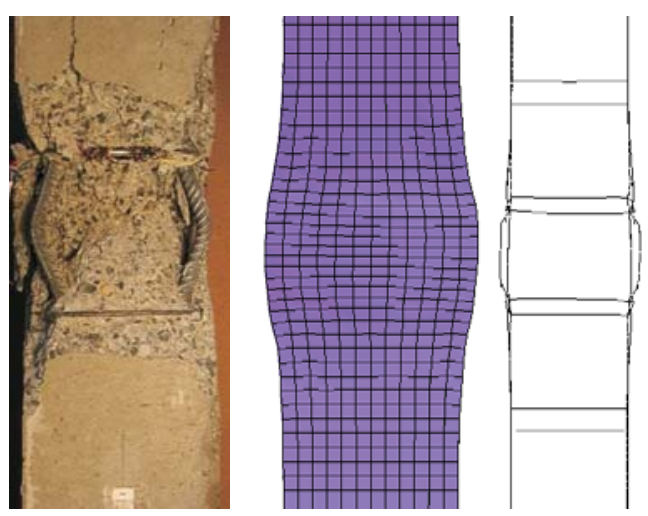

Fig. 7: Comparison of experiment (left) and FE model. Damage zone with buckled reinforcement

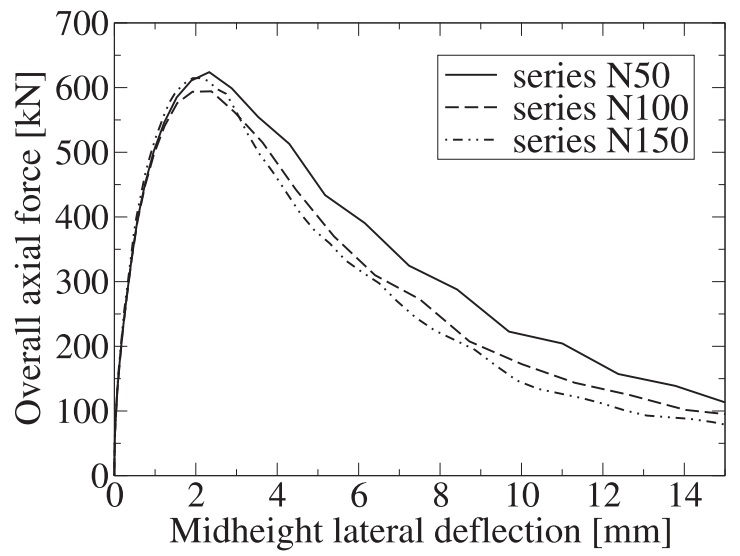

\subsection{Results of the simulation}

It was found that the model is capable of capturing all important features of RC-column behavior. It can give a good prediction of the shape and size of the damage zone in concrete and in buckling of steel (see Fig. 7). The deformation of the FE-mesh is depicted in Fig. 6, where one can see the overall deformation of the column in the post-peak phase and also the deformed reinforcement with buckled longitudinal bars between the midheight stirrups. The computed loading diagrams are shown in Fig. 8, where the overall axial force is plotted versus the midheight lateral deflection for all series.

If we perform a comparison of the computed diagrams (Fig. 8) with their experimental counterpart (Fig. 4) we can draw the following conclusions. The character of the failure, including the softening branch, is in good agreement with experiments. It lacks a yielding plateau as in the experiments, however it does not follow the slope of the experimental curve in the post-peak region. The model gives a less ductile response in this case. The peak values of the loading diagram were captured relatively well by the model. One must bear in mind that the material parameters were extracted from uniaxial compression tests only. This means that no further fitting of experimental data on the columns was done. The peak values together with the percentage change with respect

Table 7: Numerical results: peak values of midheght lateral deflection and overall axial force

\begin{tabular}{|c|c|c|c|c|}
\hline Series & $\begin{array}{c}\text { Peak } \\
\text { deflection }\end{array}$ & $\begin{array}{c}\text { Peak } \\
\text { force }\end{array}$ & \multicolumn{2}{|c|}{$\begin{array}{c}\text { Percentage change with } \\
\text { respect to experiments }\end{array}$} \\
\cline { 2 - 5 } & $\begin{array}{c}w_{\text {sim }} \\
{[\mathrm{mm}]}\end{array}$ & $\begin{array}{c}P_{\text {sim }} \\
{[\mathrm{kN}]}\end{array}$ & $\left.\begin{array}{c}\text { in deflection } \\
100\left(\frac{w_{\text {sim }}}{w_{\exp }}-1\right.\end{array}\right)$ & $\left.\begin{array}{c}\text { in peak force } \\
100\left(\frac{P_{\text {sim }}}{P_{\text {exp }}}-1\right.\end{array}\right)$ \\
\hline N50 & 2.33 & 623.9 & $-39.3 \%$ & $+1.0 \%$ \\
\hline N100 & 2.38 & 594.2 & $-35.5 \%$ & $-2.2 \%$ \\
\hline N150 & 2.10 & 614.6 & $-39.6 \%$ & $+2.1 \%$ \\
\hline H50 & 3.40 & 1096.6 & $+23.6 \%$ & $+4.1 \%$ \\
\hline H100 & 3.25 & 1059.7 & $+19.9 \%$ & $+2.1 \%$ \\
\hline H150 & 3.00 & 1053.7 & $+26.1 \%$ & $+4.6 \%$ \\
\hline
\end{tabular}

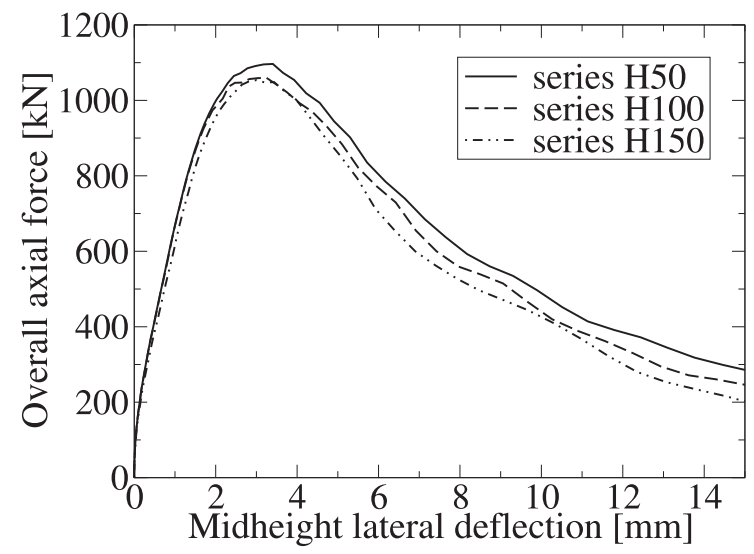

Fig. 8: Simulation: Force vs. midheight lateral deflection diagrams of $\mathrm{N}$ (left) and $\mathrm{H}$ (right) series 
to the experimental results (see Table 4) are summarized in Table 7. The values of the peak force are in excellent agreement with the experiments (within $5 \%$ ), while the peak deflections are less satisfactory (within 20-40\%).

The reason for the different results in post-peak behavior between the simulation and the experiments is probably that the concrete-steel interaction was not taken into account. No bond of reinforcement was assumed. The reinforcement modeled by beam elements was connected only to nodes of the corresponding finite element. The interaction of materials is what makes the column more ductile in the post-peak regime in comparison with only plain concrete and a plain steel structure. A consequence of this finding is that the pre-peak behavior of the columns is not very strongly influenced by the concrete to steel interaction, while for the post-peak behavior the interaction cannot be neglected. However, incorporation of the concrete/steel interaction into the model and the corresponding experimental measurements are beyond the scope of this study.

\section{Conclusions}

The behavior of six series of reinforced concrete columns with a square cross section was investigated. Two different grades of concrete (normal and high strength) and three different densities of stirrups were chosen. The columns were loaded in eccentric compression with small eccentricity. The problem was studied experimentally and numerically. A computational model based on the M4 microplane model for concrete (Bažant et al. [5], Caner and Bažant [6]) was constructed and used for simulation of the problem. The major experimental and numerical results are as follows:

- Compression failure (crushing) accompanied by concrete softening and steel buckling developed in the columns.

- Failure of columns localized into the middle part, where a wedge-shape failure pattern developed in the concrete, together with buckling of the reinforcement between the stirrups. The damage zone had approximately the same dimensions for all tested series.

- The influence of the density of the stirrups on the column strength was negligible in the investigated cases (i.e. square cross section, stirrup density $50 \mathrm{~mm}-150 \mathrm{~mm}$ ).

- A significant influence of stirrup density was observed in the post-peak region. The post-peak is characterized by the lack of a yield plateau, and the slope of the descending branch depends on the density of the stirrups. The ductility of the columns increases as the distance between stirrups becomes smaller. This was observed for both normal and high strength concretes.

- The proposed computational model based on the M4 microplane model (Bažant et al. [5], Caner and Bažant [6]) is able to provide a good description of all observed parameters, such as the shape and size of the damage process zone, the buckling of steel reinforcement, the load capacity of the structure (peak values), and the character of the post-peak behavior (decreasing load with increasing deformations).

- The computational model gives less ductility in the post-peak region, which is caused by the lack of steel to concrete interaction in the model. The model should be improved in this feature.

\section{Acknowledgments}

This work has been supported by the Czech Grant Agency (project No. 103/02/1273). This support is gratefully acknowledged.

\section{References}

[1] Bažant Z. P., Kwon Y. W.: "Failure of slender and stocky reinforced concrete columns: test of size effect." Materials and Structures, Vol. 27 (1994), p. 79-90.

[2] Bažant Z. P., Xiang Y., Prat P. C.: "Microplane Model for Concrete I.: Stress-Strain Boundaries and Finite Strain.” Journal of Engineering Mechanics, (1996).

[3] Bažant Z. P., Xiang Y., Adley M. D., Prat P. C., Akers S. A.: "Microplane Model for Concrete II.: Data Delocalization and Verification." Journal of Engineering Mechanics, (1996).

[4] Bažant Z. P., Planas J.: "Fracture and Size Effect in Concrete and Other Quasibrittle Materials." CRC Press LLC, Boca Raton, Florida, 1998.

[5] Bažant Z. P., Carol I., Adley M. D., Akers S. A.: "Microplane Model M4 for Concrete I: Formulation with Work-Conjugate Deviatoric Stress." Journal of Engineering Mechanics, Vol. 126 (2000), No. 9, p. 944-953.

[6] Caner F. C., Bažant Z. P.: "Microplane Model M4 for Concrete II.: Algorithm and Calibration.” Journal of Engineering Mechanics, Vol. 126 (2000), No. 9, p. 954-961.

[7] Brocca M., Bažant Z. P.: "Size effect in concrete columns: Finite-element analysis with microplane model." Journal of Struct. Mech., Vol. 127 ( 2001), No. 12, p. 1382-1390.

[8] Eurocode 8: Design provisions for earthquake resistance of structures, Part 1-4. Strengthening and repair of buildings. Commission of the European Communities, Brussels, 2001.

[9] Fam A., Rizkalla S.: "Large scale testing and analysis of hybrid concrete/composite tubes for circular beam-column applications." Construction and Building Materials, Vol. 17 (2003), p. 507-516.

[10] Hollingworth S. C.: "Structural and Mechanical Properties of High Strength Concrete", Ph.D. thesis, 1998, University of Wales, Cardiff.

[11] http://ksm.fsv.cvut.cz/oofem, "Finite element software OOFEM", Department of Structural Mechanics, CTU Prague.

[12] Jirásek M., Bažant Z. P.: "Inelastic Analysis of Structures.” John Wiley \& Sons, UK, 2002.

[13] Němeček J., Bittnar Z.: "Experimental Investigation and Numerical Simulation of Post-Peak Behavior and Size Effect of Reinforced Concrete Columns." Materials and Structures, Vol. 37 (2004), No. 67, p.161-169.

[14] Němeček J.: "Modeling of Compressive Softening of Concrete", Ph.D. thesis, CTU reports, 2000, Prague.

[15] Němeček J., Patzák B., Rypl D., Bittnar Z.: "Microplane models: computational aspects and proposed parallel algorithm." Computers and Structures, Vol. 80 (2002), p. 2099-2108.

[16] Mortazavi A. A., Pilakoutas K., Son K. S.: "RC column strengthening by lateral pre-tensioning of FRP." 
Construction and Building Materials, Vol. 17 (2003), p. 491-497.

[17] Ouyang C., Shah S. P.: "Fracture Energy Approach for Predicting Cracking of Reinforced Concrete Tensile Members." Structural Journal ACI, Vol. 91 (1994), p. 69-78.

[18] Patzák B.: "Material models for concrete", Ph.D. thesis (in Czech), CTU Prague, 1997.

[19] Patzák B.: "Object Oriented Finite Element Modeling." Acta Polytechnica, (1999), Prague.

[20] Řeřicha P.: "Optimum Load History for Non-linear Analysis Using Dynamic Relaxation." Journal of Structural Mechanics, Vol. 23 (1986), p. 2313-2324.

[21] Sener S., Barr B. I. G., Abusiaf H. F.: "Size-effect tests in unreinforced concrete columns." Magazine of Concrete Research, Vol. 51 (1999), No. 1, p. 3-11.

[22] Van Mier J. G. M.: "Strain-softening of Concrete under Multiaxial Loading Conditions", Ph.D. thesis, Eidhoven University of Technology, The Netherlands, 1984.
[23] Vonk, R.: "Softening of concrete loaded in compression", Ph.D. thesis, Technische Universiteit Eindhoven, 1992.

Ing. Jiří Němeček, Ph.D.

email: jiri.nemecek@fsv.cvut.cz

Ing. Pavel Padevět, Ph.D.

Prof. Ing. Zdeněk Bittnar, DrSc.

phone: +420 224354309

fax: +420224310775

Department of Structural Mechanics

Czech Technical University in Prague

Faculty of Civil Engineering

Thákurova 7

16629 Prague 6, Czech Republic 